\title{
Modelling of Socially Responsible Pareto-Effective Stakeholders Interaction Formation under the Mass Media Influence
}

\author{
Ghandir Hatem \\ Department of Public Administration \\ and Management \\ Ivano-Frankivsk Natonal Technical \\ University of Oil and Gas \\ Ivano-Frankivsk, Ukraine \\ ipo.pvp@gmail.com
}

\author{
Mark Liuty \\ Department of Public Administration \\ and Management \\ Ivano-Frankivsk Natonal Technical \\ University of Oil and Gas \\ Ivano-Frankivsk, Ukraine \\ ipo.pvp@gmail.com \\ Oleh Yatsiuk* \\ Department of Economics and \\ Management Theory \\ Ivano-Frankivsk Natonal Technical \\ University of Oil and Gas \\ Ivano-Frankivsk, Ukraine \\ olegstya@gmail.com \\ https://orcid.org/0000-0002-3943-7352
}

\author{
Sviatoslav Kis \\ Department of Economics and \\ Management Theory \\ Ivano-Frankivsk Natonal Technical \\ University of Oil and Gas \\ Ivano-Frankivsk, Ukraine \\ svjatkis@gmail.com
}

\begin{abstract}
The purpose, role and functions of modern mass media influence on all socially significant components of society by forming in the last public opinion, aimed at a joint search for pareto-efficient solutions of sustainable development, are yet to be subjected to further thorough scientific and theoretical analysis. The new directions of scientific research in the field of management technologies based on the integration and harmonization of collective intelligence have been generated and widespread due to mass media dissemination of information, on the collective, participative, partnership management and leadership, on crowdsourcing and cognitive technologies, which form a new interaction paradigm between society and state as a way of cognitive behavior transformation of the individual, their groups and organized groups, nations and states through massive attraction and use their intellectual potential in combination with modern information systems. Spatial model of the search for a pareto-optimal point of cost-effective market interaction of three participants in market transactions on the surface of utilitarian possibilities and the model of socially responsible pareto-effective stakeholders interaction formation in the socio-economic system under the mass media influence are developed in the paper.
\end{abstract}

Keywords-pareto-optimal point, market interaction, efficiency, potential, mass media.

\section{INTRODUCTION}

The new information technologies and technical means through which the mass media was formed in their modern sense, have created opportunities for influencing the public consciousness due to the influence on the consciousness of an individual and groups, on the collective consciousness of the personnel and authorities of the various organizational entities. At the same time, not being an independent force capable of programming and implementing progressive transformations, useful reforms and necessary social changes on a large scale, the mass media shall contribute both to the processes of decay of past epochs leading ideas and to the growth of new concepts popularity.

In this regard, the potential of mass media can be used in two main directions:

- the influence of mass media on the society, where the mass media is dependent on a number of actors such as the legislative, executive and judicial structures of the acting authorities, alternative political forces, civil society organizations, business structures, etc., in connection with which the problem of protecting people from possible manipulations and confronting propaganda of individual subjects arises;

- the influence on society and on all the aforementioned subjects of the independent media, which become the speakers of society interests as a whole (and not only of the above-mentioned constituents), and form the decisions necessary for the whole society of the authorities, business and consumers regarding the achievement of the desired level of social, economic and ecological welfare.

\section{ANALYSIS OF DOMESTIC AND FOREIGN}

PublicAtions AND ILlumination OF THE PREVIOUSLY

UnSOLVED PART OF THE GENERAL PROBLEM

If, within the direction of using the mass media potential by the authorities and business structures for the formation of the necessary market behavior of consumers, the study of opportunities, technologies and mechanisms already exists $[1,2]$, then the studies of the possibilities of the reverse influence of the mass media on the formation of socioresponsible behavior of the authorities, business and consumers, when the media "live in unison with the needs of the country and its ordinary citizens" [3] are practically absent. 
Although partly the answers to the question of what power the media possesses, who actually controls them, and what the relationship between the media, the authorities and the society have already been given by the author of the research work [4] the scientific recommendations in this precise direction of managerial communication of the media, institutions of power, business and civil society require in-depth research and substantiation of the real possibilities and mechanisms of effective media impact on the state and business in the interests of society.

It is worth noting that at one point the author of this research work [5] uses the well-known provisions and graphic model of Wilfredo Pareto on finding and setting up effective interaction between a pair of market partners in a competitive environment [6; 7, p. 94-95; 8, p. 526-527], formulated recommendations for possible options for optimizing the interaction of so-called key groups or stakeholders of national economies, interpreted by Pareto in the form of three sets - parties from power, business and consumers. In developing these recommendations, other researchers examined the practical ways of establishing the interaction of these sets to optimize the sharing of financial, regional [9], techno-technological and other resources. However, the conditions for the formation of socially responsible behavior of these sets, for observance of which such harmonized and adjusted interaction becomes possible, as well as sources of influence with the highest potential of their formation, which in the modern information media are the media, remain without the attention of the authors of these works.

\section{THE PURPose OF THE PAPER}

The purpose of the research work is to find and identify opportunities for the effective use of national mass media potential in the processes of managing national economies in order to improve their functioning and increase competitiveness in the global marketplace.

\section{Main Body OF THE Research MATERIAL}

According to the conditions of interaction in the competitive market environment of the two sides with the function of "supplier - consumer", the mutual relations within each separate pair can be represented in the form of a dependence called "curve of utilitarian opportunities" from a well-known theory of welfare economy with the finding of the optimal exchange at a fair price and pareto-effective interaction for both participants, the author of which is Wilfredo Pareto [6].

This curve (Figure 1) describes the process of finding mutually beneficial and mutually acceptable cooperation between two counterparts in a market environment.

At the same time, the so-called pareto-optimal point (POP1-2) of a bilateral and mutually beneficial exchange at a fair price for both parties is a point in which the relations between the parties are considered to be both economically profitable and acceptable for both parties, and the resulting economic exchange results are close to optimal (zone between $\mathrm{POP}_{1}$ and $\mathrm{POP}_{2}$ ).

The transfer of $\mathrm{POP}_{1-2}$ along the utilities curve should not take place due to unilateral decisions or actions of the participants, which may lead to its withdrawal from the zone of mutual trust and benefit. After all, for example, in the case of moving a pareto-optimal point from the $\mathrm{POP}_{1}$ position to the $\mathrm{POP}_{2}$ position, which occurred under the action of the 1st Party without the agreement of the 2nd Party, and resulted in an increase in its benefit by $+\Delta 1$, it will necessarily lead to a corresponding reduction of the $2 \mathrm{~ns}$ Party's profit 2 to $-\Delta 2$.

In the same (only reverse) order, a change in these values may occur due to the 2nd Party's uncoordinated actions towards the 1st Party.

Thus, the transfer (if necessary) of $\mathrm{POP}_{1-2}$ should take place only with the consent of the parties, while rational, effective and efficient interactions between parties 1 and 2 (Figure 1) are possible only with the maximum integration of the diverse interests of the parties on the basis of cooperation and the search for compromises, which is possible under the following two conditions:

- the presence of well-coordinated, that is, regulated, formalized and algorithmic relations in the form of policies, laws, regulations, regulations, procedures and rules;

- the presence on both sides of goodwill to maintain and maintain these relationships in the $\mathrm{POT}_{1-2}$ zone in the framework of existing regulations, as well as generally accepted human values, morals and spirituality.

If the first condition is necessary but not sufficient for the formation and provision of interactions with positive results for both parties, then the second - the presence of goodwill of the parties - requires further clarification.

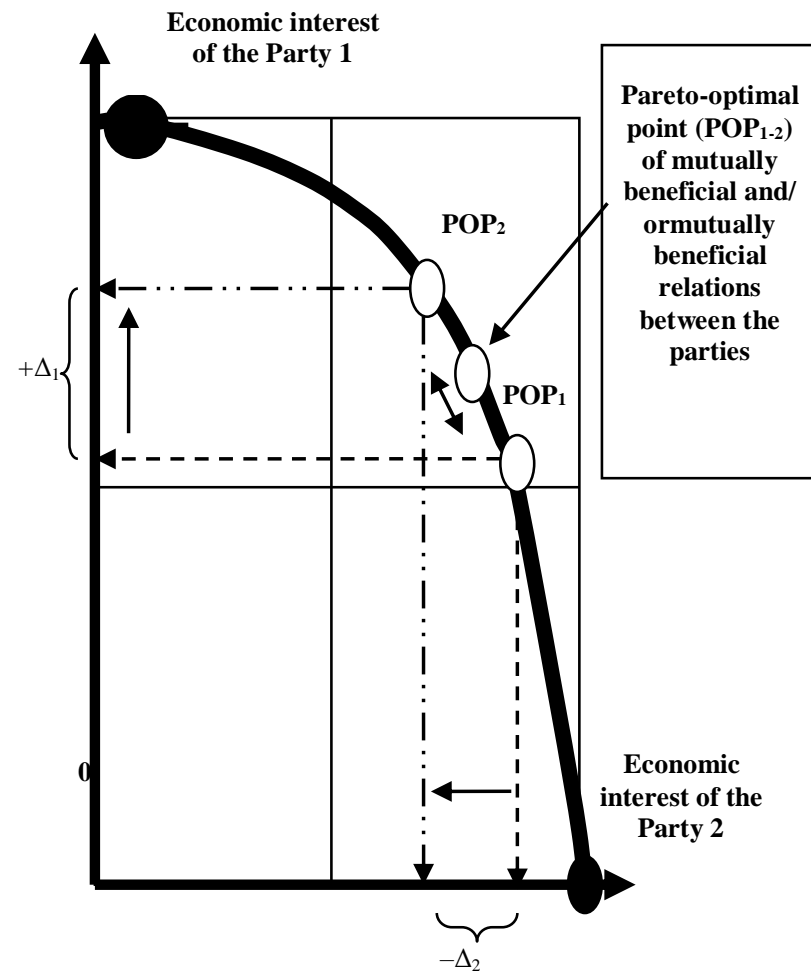

Fig. 1. Geometric model of the rationale for the achievement of pareto-optimal relationships within the framework of the interaction of two market agents "Party 1 - Party 2" [6] 
Taking as an axiom the fact that parties 1 and 2 function with mutual obligations to find and maintain favorable for them values of $\mathrm{POP}_{1-2}$, and guarantees of the market environment (policies, laws, etc., and the "goodwill" formed on their basis) are stable, the assumption that the parties may have other interests, goals and motives of functioning can be considered unlikely.

By extending these conditions of pareto-effective (not optimal) relationships to the interpretation of the interaction and mutual relations between all the participants in market relations (the state - producers - consumers), within each particular pair, we obtain the corresponding plane graphanalytic models that reflect the relationship between the pairs Party 1 (the state) - Party 2 (business) (a), Party 2 (business) - Party 3 (consumers) (b) and Party 3 (consumers) - Party 1 (state) (c) in Figure 2.

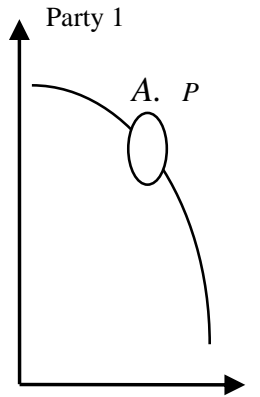

a) Party 2

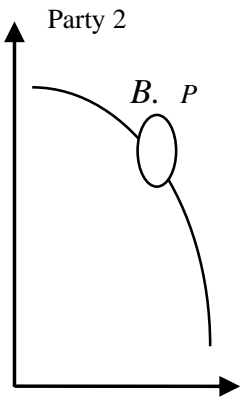

b) Party 3

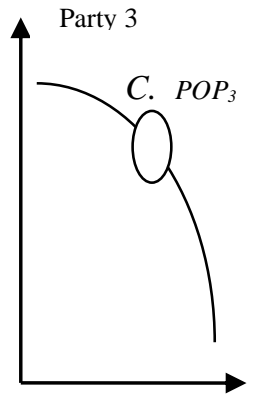

c) Party 1
Fig. 2. Distribution of the conditions of pareto-effective relations on three interacting multy-participants
In this way, in each individual case, in the process of interaction of the parties there are corresponding paretooptimal points, which refer to their interactions and correspond to the existing conditions on their interaction in the market, determined by the above conditions of goodwill for maintaining these relations in the zone $\mathrm{POP}_{1-2}$ in the framework of existing regulations.

Using the principle of superposition - overlaying processes with the consequences of the emergence of new constructive or destructive effects - we obtain a spatial model of reasonable interaction in the relations of the three parties, in which each side agrees its behavior with the other two.

As a result of this operation, we obtain a spatial model of the search for a pareto-optimal point of cost-effective market interaction between the three participants in market transactions on the surface of utilitarian opportunities, which is formed in the space of Cartesian coordinates, as suggested in [7] to substantiate the possibility of optimizing tripartite relations between the state and producers of economically significant products and consumers on the basis of a model for achieving pareto-efficient interactions.

Spatial model of the search for a pareto-optimal point of cost-effective market interaction of three participants in market transactions on the surface of utilitarian possibilities (reinterpretation of the author J. Stiglitz [7])Thus, a reinterpretation of the well-known model with regard to the conditions for organizing effective interaction within the framework of the "supplier - state - consumer" allowed us to obtain a spatial model of the utilization potential and utility surface for all participants in the management interaction process through joint decision making that is presented by us in Figure 3.

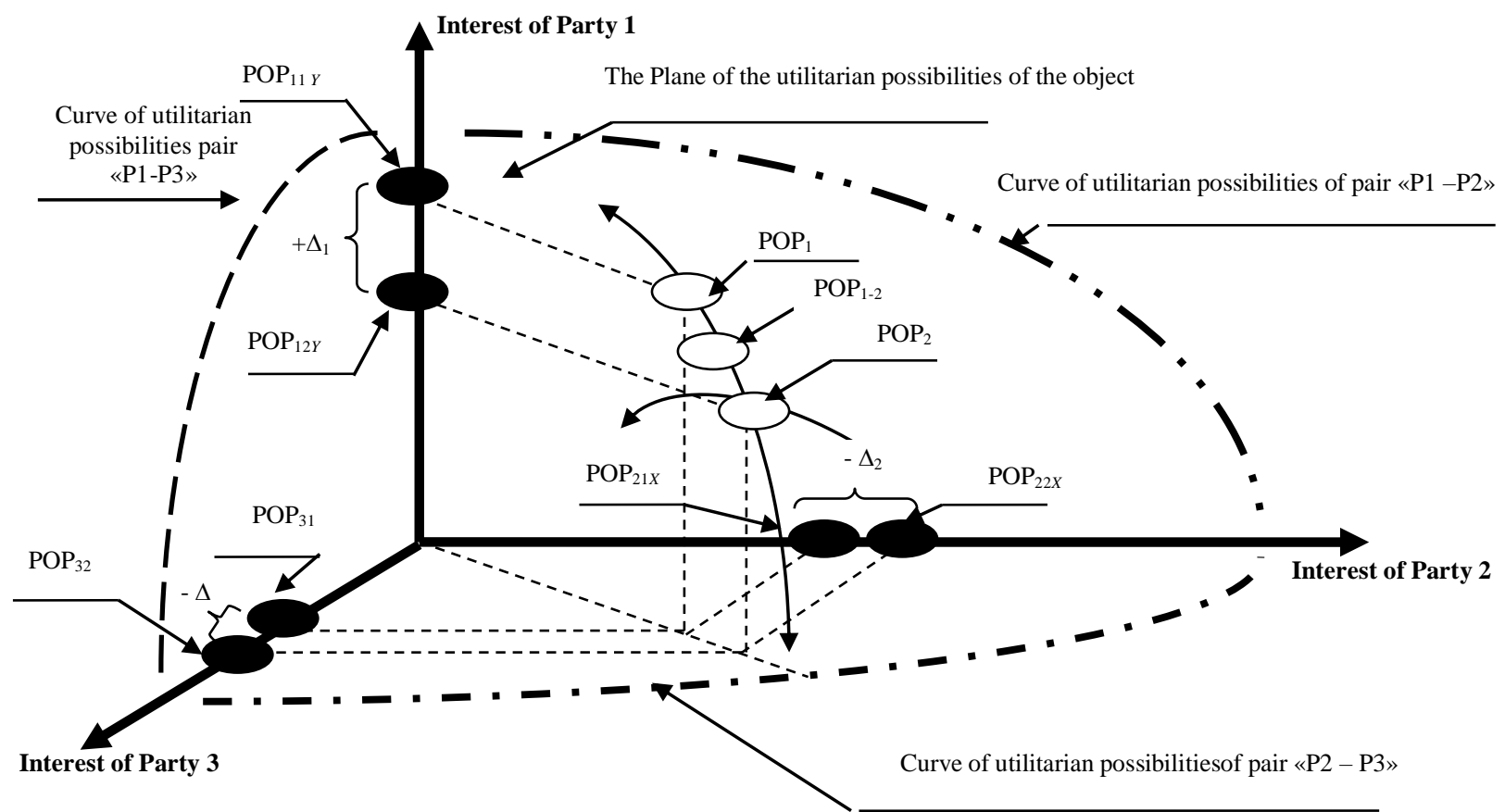

Fig. 3. Spatial model of the search for a pareto-optimal point of cost-effective market interaction of three participants in market transactions on the surface of utilitarian possibilities (reinterpretation of the author J. Stiglitz [7]) 
At the same time, the situation shown in Figure 3 illustrates the fact that in the case of an individual decision to increase its own benefit $(+\Delta 1)$ by Party 1 , the negative consequences for the interests of Party $2(-\Delta 2)$ and Party $1(-$ $\Delta 3$ ) are compulsorily occurring. There are other options for redistributing the benefits of all three parties, which will correspond to the point $\mathrm{POP}_{1-2-3}$.

Continuing the analysis of possible options for the behavior of Parties 1, 2 and 3 in the proposed spatial model, it is easy to conclude that any one-way actions aimed at improving one's own position by any single Party will lead to negative consequences and losses:

- for both other Parties with an approximate parity of deterioration in their performance indicators;

- for one of the Parties with a multiple increase in losses provided that the interests of the other party are preserved.

It is also possible for two parties to collude in order to improve common positions at the expense of the third party.

In this case, it is obvious that the Party that is the victim of the conspiracy of the other two will incur losses proportional to the benefits received by the participants in such a conspiracy.

Therefore, achieving pareto-optimal values of the results of trilateral cooperation is a common concern of the governing bodies of all three subjects of economic cooperation.

Thus, if the spatial model of organization of paretoefficient market relations between participants of the statebusiness-consumer triad was proposed by the author of the paper [6] to demonstrate the fact that in the process of making decisions about its activities in a single market space all participants should try to avoid mutual damage and, conversely, to obtain acceptable results for all the interaction, then in this case we have demonstrated that the pareto-efficient interaction of the three business entities with the receipt of the positive results for all participants requires the cooperation of the latter on the basis of the search and implementation of consensus and/or compromise solutions.

Thus, it becomes obvious that the joint achievement of an acceptable level of utility for three sets of participants is only possible if the proper communication and interaction between the authorities, business and consumers of their services is conducted, requires a clear determination of the conditions that will ensure compliance with it. Two following questions need to be answered for this:

- Can such socially significant components of society as the mass media act as the subjects of forming socially responsible behavior of such objects as power, business and consumers within national economic?

- What goals shall be declared and pursued by the media to improve the functioning and increase the competitiveness of national economic in the context of key market players?

Given that information is a means of influencing changes and upgrades of aging systems through the search for and implementation of new approaches and solutions, it is clear that it is the mass media that through the dissemination of information can affect the activities of all branches, institutions and officials of power, business, political parties and politicians, to identify mistakes, miscalculations or other intentions, and to mobilize public opinion for the correct assessment and the fight against these phenomena. After all, when the authorities, businesses, officials, political and public figures, citizens, changed views, positions, public opinion, political and economic decisions under the influence of widespread mass media information are well-known.

Since the mass media has powerful capabilities for influencing people's consciousness and behavior, this gave rise, along with the legislative, executive and judicial branches of power, to call them the fourth branch [13], with the difference that the "fourth power" was deprived of coercion means.

However, shaping the public opinion, which is a reflection of the attitude of country population (both in general and individual communities) to the activity of the authorities, business, political parties, public organizations, etc., the "fourth power" to some extent acts as the subject of influence and the plurality of power structures, business participants and consumers of their services.

In this regard, in a society with a market economy, freedom of speech and pluralistic democracy, all types of mass media are and should remain dispersed both among different political forces and among different business groups in order to provide the same checks and balances system as in the mechanism of state power.

At the same time, in a democratic society, commercial, party, public and state mass media as subjects of the formation of socially responsible behavior of objects of influence (sets of partners from power, business and consumers) must, by all means, motivate these sets to search for harmonized and harmonized by providing them with the necessary, sufficient and adequate information, self-control and control over the authorities and political forces in whose hands they are, over parties and politicians, over business groups.

Therefore, in spite of the fact that in the democratic societies the main functions of the commercial mass media are the advertising of goods and services, the party propaganda and propaganda on the dissemination of political programs, ideas and slogans, public - an adequate reflection of the processes of social existence, and state the performance of functions an information intermediary between society and the state common to all these components can and should become a function of forming socially responsible behavior of objects of influence from the sets of power, business and consumers achieve Paretoefficient points $\left(\mathrm{POP}_{1-2-3}\right)$ in the area of intersection of the goals and interests of all participants (Figure 4).

Thus, mass media functional influence in a democratic society, which, although determined by the position of their founders in the political system, is intended to create a kind of informational space, in which the plurality of objects of power, business and consumers will motivate and encourage all participants to jointly develop, adopt and implementation 
of solutions aimed at socially responsible goals and interests of the whole society, and not individual parts of it.

In this case, functionally not being the subjects of management of the vital functions of society, mass media resources have the potential of forming public opinion, which, in turn, will influence the decisions and behavior of the management bodies by the plurality of actors:

- $\quad$ public administration;

- $\quad$ business units and all their possible associations;

- civil society organizations.

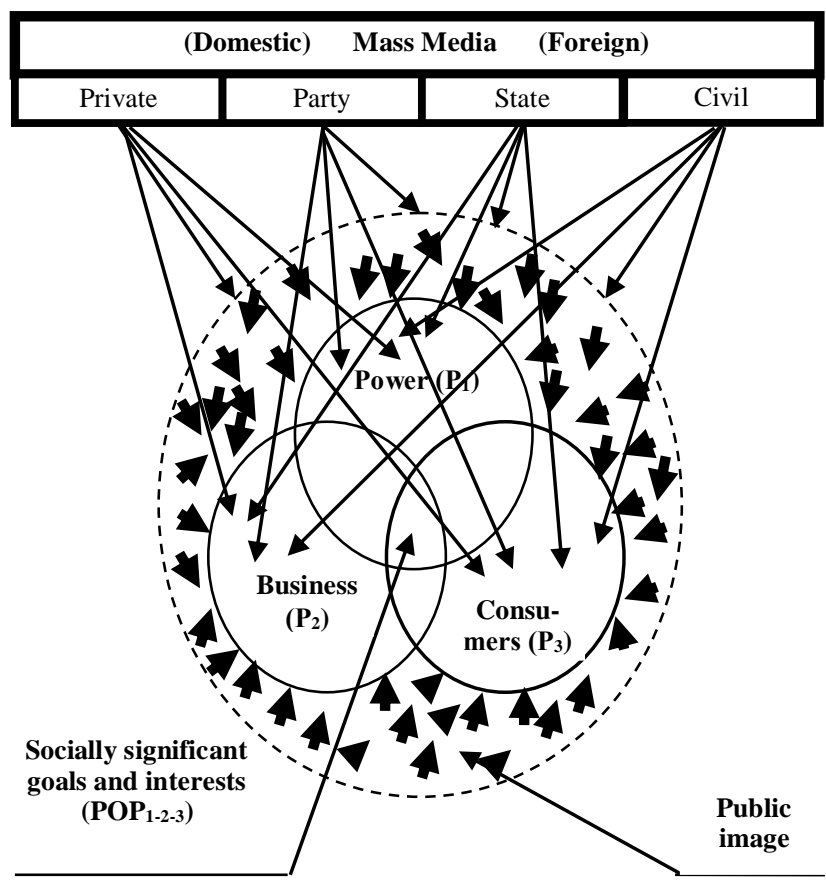

Fig. 4. Model of formation of stakeholders socially responsible pareto-effective interaction under mass media influence (authhor's interpretation)

Thus, media actors plurality in all multivectoral purposes and interests of their owners must adhere to a certain unity in one - the goals and interests of their owners should not dominate the goals and interests of the whole society, which are regulated by laws and regulations of this the same society.

Any other media action (disinformation, manipulation, fake, etc.) is counter to system interests as it will lead to destabilization of its economic and therefore social and environmental efficiency with all negative consequences, examples of which are observed in nondemocratic societies worldwide.

\section{CONCLUSION}

The purpose, role and functions of modern mass media influence on all socially significant components of society by forming in the last public opinion, aimed at a joint search for pareto-efficient solutions of sustainable development, are yet to be subjected to further thorough scientific and theoretical analysis. However, today it can not be denied that the new directions of scientific research in the field of management technologies based on the integration and harmonization of collective intelligence [9] have been generated and widespread due to mass media dissemination of information, on the collective, partisipative, partnership management and leadership [10,11, 12], on crowdsourcing [13] and cognitive (cognitive) technologies [14, 15], which form a new interaction paradigm between society and state as a way of cognitive behavior transformation of the individual, their groups and organized groups, nations and states through massive attraction and use their intellectual potential in combination with modern information systems and technologies.

\section{REFERENCES}

[1] Yu. Horban, "The Newest Communication Opportunities in Interaction of Mass Media, Public Authorities and Public Organizations", Bulletin of the National Academy of Public Administration under the President of Ukraine, № 4, p. 38-45, 2013. [in Ukrainian].

[2] P. Verbytskyi, "Interaction of public authorities and mass media as a category of social communication science", Dialogue: media-studios, vol. 22, p. 17-28, 2016. [in Ukrainian]

[3] M. Pietzukh, "Media did not betray the Poles, and the Poles reciprocated by supporting their wallet and ratings. Independent Media as the First Power: Recipe for Ukraine", Detector Media, 2011. [Online]. Available: https://detector.media/rinok/article/64073/201107-05-mas-media-ne-zradili-polyakiv-i-polyaki-vidpovidayut-imvzaemnistyu-pidtrimuyuchi-gamantsem-tirazhi-i-reitingi/

[4] J. Curran, Media and Power. London. Routledge, 2012. [Online]. Available: https://www.taylorfrancis.com/books/9780203417744

[5] V. Petrenko, "Towards determining ways to optimize relations between the state, producers and consumers using the laws of the Pareto-efficient market”, Scientific Bulletin IFNTUOG, № 4, p. 71-76, 2002. [in Ukrainian].

[6] V. Pareto, Compendio di sociologia generale. Firenze, Italia: Nuova Universale Einaudi. N.S., 1978. [in Italian].

[7] J. Stiglitz, and J. Rosengard, Economics of the public sector. (4rd ed.), New York, London: W. W. Norton \& Company, 2015.

[8] M. Blaug, Economic Theory in Retrospect. Cambridge, USA: Cambridge University Press, 2018. [Online]. Available: https://www.cambridge.org/core/books/economic-theory-inretrospect/0D3D1C6934A23E9CE4A56A95DD879B18

[9] V. Vartsaba, Regional management: theory and practice of harmonization of goals and interests of power, science, business: monograph. Ivano-Frankivsk, Ukraine: IFNTUOG, 2015. [in Ukrainian].

[10] E. Armstrong, The Role of Active Participation and Citizen Engagement in Good Governance. New York, USA: UN Public Administration Programme, 2013. [Online]. Available: https://www.un.org/esa/socdev/egms/docs//2013/EmpowermentPolici es/Elia\%20Armstrong\%20presentation.pdf

[11] Project "Party-based Democratic Democracy and Ground-Based Decisions in Ukraine. Conclusions and Results", Bulletin of the Association of Ukrainian Cities, № 153, 2018. [in Ukrainian].

[12] P. Kuenkel, The Art of Leading Collectively: Co-creating a Sustainable, Socially Just Future. USA: Chelsea Green Publishing, 2016.

[13] O. Kravtsov, "Using of crowdsourcing in modern public administration", Public administration and local self-government, № 4, p. 15-23, 2014. [in Ukrainian].

[14] I. Dror, Cognitive Technologies and the Pragmatics of Cognition. Amsterdam, The Netherlands: John Benjamins Publishing Company, 2007.

[15] Yo. Khromyak, Yu. Slyusarchuk, L. Tsymbal, and V.Tsymbal, "Cognitive technologies and their features in the management and in the marketing", Bulletin of the National University "Lviv Polytechnic". Management and entrepreneurship in Ukraine: stages of development and development problems, № 767, p. 75-82, 2013. [in Ukrainian]. 